\title{
Influence of WeChat Use on the College Students Campus Life Satisfaction-A Perspective on Bridging Social Capital
}

\author{
Ranni Zhang ${ }^{1,2,3}$, Yuxin Zheng ${ }^{3}$, Ze Chen ${ }^{3}$, Bin Li ${ }^{4}$, Songping Yang ${ }^{5}$ \\ ${ }^{1}$ School of Journalism and Communication, Jinan University, Guangzhou, China \\ ${ }^{2}$ School of Marxism, Jinan University, Guangzhou, China \\ ${ }^{3}$ School of Humanities, Jinan University, Zhuhai, China \\ ${ }^{4}$ Zhuhai City Polytechnic, Zhuhai, China \\ ${ }^{5}$ Zhuhai Campus, Jinan University, Zhuhai, China \\ Correspondence: Songping Yang, Qianshan Road, Zhuhai Campus, Jinan University, Zhuhai, China.
}

Received: May 4, 2019

doi:10.11114/smc.v7i1.4295
Accepted: May 26, 2019

Online Published: May 27, 2019

URL: https://doi.org/10.11114/smc.v7i1.4295

\begin{abstract}
The theories of social capital and Rosenberg's self-esteem scale were used to measure the campus life satisfaction of college students, this paper made an empirical analysis on the WeChat media use of 1000 college students from Hong Kong, Macao, Taiwan and mainland China $(\mathrm{M}=18.81$ years old, $\mathrm{SD}=0.96)$ of a University in Guangdong province, and discussed the relationship among college students' social media use intensity, campus life satisfaction and social capital. The study found that there was a significant positive correlation between WeChat use intensity of college students and social capital, that the intensity of WeChat use had a direct effect on college students' satisfaction with campus life, and that self-esteem had a moderating effect between WeChat use intensity and social capital.
\end{abstract}

Keywords: college students, WeChat use, social capital, campus life satisfaction

Taking WeChat as the representative, social media has been embedded into all aspects of mass interpersonal communication and social participation. It not only has the function of information transmission and communication media, but also integrates functions beyond mass media and interpersonal communication media. At present, the research on WeChat communication for teenagers mainly focuses on communication, psychology and pedagogy, focusing on the network media literacy of college students, the characteristics of college students ' circle of friends, the information disclosure and privacy rights of WeChat Moments, the network ethics and so on. And the relationship between WeChat use of college students and campus life satisfaction is rarely seen in the research field. Based on the theoretical perspective of social capital, this study takes WeChat use as the research background and rosenberg self-esteem scale as the measurement, and explores the relationship between WeChat use of college students and campus life satisfaction with the method of empirical research. By aiming at the survey data of students from Hong Kong, Macao and Taiwan and mainland China in a University located in Guangdong, it is concluded that the regression analysis $(\mathrm{N}=983$, effective recovery rate is $98.3 \%$ ) showed that there is a strong correlation between WeChat use and three types of social capital, and is most closely related with the Bridging social capital. In addition, WeChat use had certain interaction with the mental health of college students, suggesting that social media helps college students with low self-esteem integrate into college life.

\section{Social Capital and WeChat Use of College Students}

\subsection{Social Capital: Community Social Capital and Online Social Capital}

Social capital has specific definitions in different fields. Generally, social capital refers to resources accumulated through interpersonal relationships. Bourdieu and Wacquant (1992) define social capital as the sum of resources, actual or virtual resources, accumulated to individuals or groups through a persistent network of more or less institutionalized mutual knowledge and recognition. The resources in these relationships can vary depending on the form and function of the relationship itself. The concept of collateral strength was first proposed by Mark Granovetter in 1973, who classified relationships as strong tie and weak tie, depending on the intensity, for strong tie, he defines it as a relationship established between homogeneous individuals, which was manifested as a repeated and identical information transmission; while 
weak tie exist between heterogeneous individuals, enabling individuals to break through the limitations of their social groups, and access to new information in society so as to realize the advantages of social mobility to apply for a job, which he elucidated that "broader but superficial social perception", which means that members are more likely to have access to additional resources to support their instrumental actions, can promote competition between them and some new information is disseminated in this type of relational network.

In presenting the theoretical framework of "strong tie -- weak tie", Granovetter (1973) once divided the construction of the relationship into four components: the amount of time, the emotional intensity, intimacy and reciprocal services. In his opinion, strong tie is a kind of relationship network within the social group, which is conducive to increase the cohesion of the network. Weak tie, on the other hand, is a kind of "bond", which mainly acts between individuals within the group and is a kind of social connection on a larger scale. Based on his theory, Burt RS. (1997) put forward the arguments and evidence of the ecology of social capital structure and described the mechanism by which the value of social capital to individuals depends on the number of people doing the same job. On this basis, Paul AS et al. (2002) constructed a conceptual framework to identify the sources, benefits, risks and unexpected situations of social capital. Another study that discussed the major sources of social capital and the structure of communication networks was carried out by Sun Kyong Lee et al. (2014), this study was based on Smith's (1999) theoretical proposition on cross-cultural communication networks and tested seven hypotheses. At the same time, the whole network of the organization was constructed by the survey of the organization members of Korean immigrant churches $(\mathrm{N}=178)$. In addition, they mainly use hierarchical regression model analysis. The results show that, regardless of the individual's willingness to immigrate, the excessive embedding of intercultural communication networks will increase one's ethnocentric cultural attitudes and beliefs. Zhou zongkui et al.(2017)explored the relationship between the use of social networking sites, online social capital, self-esteem and life satisfaction of adolescents, and found that the use intensity of social networking sites was significantly positively correlated with online connected/bridged social capital and life satisfaction. At the same time, compared with teenagers with low self-esteem, the use of social networking sites is more beneficial for teenagers with high self-esteem to obtain online social capital. Based on the interview data of Chinese and American employees, Michael W. Kramer, Sun Kyong Lee, \& Yijia Guo (2018) discussed how to collect and provide information under new technical conditions and how to manage their self-image. These data reflects two similar results under different cultural background, but about work, relationship and organizational management of uncertainty, the staff are concerned about the two countries through the display specification in the technology USES technology to use and appropriate professional - balance of personal life to show positive image.

\subsection{Social Capital and WeChat Use of University Students}

There is a close relationship between the social capital of college students and the use of WeChat. As the basis of weak connection and bridge of social capital, subsequent studies have been conducted on the relationship between internet-based network social behavior and social capital. Based on Mark Granovetter (1973) theory of "weak ties" and Putnam proposed "in general, social capital is regarded as the positive effect of interaction between social network participants" this view (Putnam, 2004), B. Ellison et al.(2006)conducted a regression analysis on the correlation between the use of Facebook by college students and social capital, and proposed that the use of Facebook has a strong correlation with three kinds of social capital, and has the highest correlation with communication social capital. At the same time, Facebook use was found to interact with measures of mental health, meaning that it offered greater benefits to users with lower self-esteem and life satisfaction. Jin $\mathrm{CH}$ further the use of online social network bridge and the link of social relations, and discusses the effect of social capital, examines the Facebook users self system (including self-efficacy, your personal opinion, social presence and self-esteem four elements) and using strength how to influence the effect of social relations and social capital. He argues that Facebook users' self-systems play an important role in forming, connecting and generating social capital. From the perspective of individual expression, Yu Xin (2014) believes that the expression of college students' opinions on the Internet is significantly affected by social capital. The higher the bridge-type social capital, the stronger the will of public expression. Cao Chang (2015) and other researchers conducted qualitative research on the WeChat Posting behavior of college students in the WeChat friend circle, and concluded that college students' Posting in the WeChat friend circle included self-performance of "my style and my show" and social soliloquy of roll call game. Today's knowledge transfer is much easier, and because of the features of corporate social networking sites that make someone's communications visible, people can learn a lot just by watching his or her online behavior, even if they never interact directly with each other. This simple awareness of others' communication is defined by Paul M. Leonardi and Samantha R. Meyer (2015) as environmental awareness, and it is pointed out that this awareness plays a key role in helping learners acquire interpersonal and knowledge-related materials, which can increase their interaction with the source of knowledge. Paul M. Leonardi (2017) argues that social media has begun to influence many organizational phenomena and processes. Based on the review and discussion of previous studies, the study provide a theoretical 
framework based on the concept of availability for the study of social media, which is conducive to the discussion of the potential impact of social media use on organizations through theoretical studies in the future.

\section{The Research Hypothesis of WeChat Intensity and Bridging Social Capital of College Students}

In view of the above literature review and clarification of the relationship between WeChat use and social capital, the following hypotheses are proposed in this study:

H1: There is a positive correlation between WeChat use intensity of college students and bridging social capital.

$\mathrm{H} 2$ : There is a positive correlation between college students' self-esteem and bridging social capital.

H3: There is a positive correlation between college students' campus satisfaction and bridging social capital.

H4: WeChat use intensity of college students and bridging social capital are moderated by self-esteem.

H5: WeChat use intensity of college students and bridging social capital are moderated by campus satisfaction.

2.1 The Demographic Variables and Main Research Variables of WeChat Use Intensity of College Students and Bridging Social Capital

In order to explore the relationship between WeChat use intensity of college students and bridging social capital, the research framework formed by taking college students' satisfaction with campus life and self-esteem as interfering variables and regulating the above two relations is as follows:

Table 1. Correlation analysis of demography and main research variables

\begin{tabular}{|c|c|c|c|c|c|c|c|c|c|}
\hline & & 1 & 2 & 3 & 4 & 5 & 6 & 7 & 8 \\
\hline 1. Gender & & 1 & & & & & & & \\
\hline 2. Age & & -.041 & 1 & & & & & & \\
\hline 3. Source Land & & $-.160 * *$ & $.115^{*}$ & 1 & & & & & \\
\hline $\begin{array}{l}\text { 4. intensity } \\
\text { WeChat use }\end{array}$ & of & .090 & .036 & .085 & 1 & & & & \\
\hline $\begin{array}{l}\text { 5. WeChat } \\
\text { behavior social }\end{array}$ & use & -.025 & .008 & $.179 * *$ & $.636 * *$ & 1 & & & \\
\hline 6. Self-esteem & & .045 & .052 & -.058 & $.364 * *$ & $.259 * *$ & 1 & & \\
\hline $\begin{array}{l}\text { 7. Campus } \\
\text { Satisfaction }\end{array}$ & Life & $-.136 * *$ & -.022 & $.107 *$ & $.244 * *$ & $.327 * *$ & $.385^{* *}$ & 1 & \\
\hline $\begin{array}{l}\text { 8. Bridging } \\
\text { capital }\end{array}$ & social & -.073 & -.06 & -.016 & $.402 * *$ & $.342 * *$ & $.548 * *$ & $.552 * *$ & 1 \\
\hline
\end{tabular}

\subsection{A Sample Survey on the Relationship Between WeChat Use Intensity and Social Capital of College Students}

A structural questionnaire survey was conducted among college students in guangdong province. Before the formal survey, 1000 college students were invited to make a predictive test on the questionnaire, and all variables showed good reliability. Stratified sampling and cluster sampling were adopted to collect samples. Random sampling was conducted according to dormitory buildings, Taking the dormitory as the sample, each student in the dormitory was selected to fill in the questionnaire. In order to expand the coverage of the sample, a university in Guang Dong with students from the three regions of mainland China and Taiwan was selected as the starting point of the questionnaire, trying to cover the interviewees from different grades and different places of origin as much as possible to ensure the heterogeneity of the sample. The researchers disseminated the information through the network and sent out questionnaires to students of all grades through the questionnaire star, and successfully recovered 983 valid questionnaires, with an effective recovery rate of $98.3 \%$. The effective samples included 385 men $(39.34 \% ; \mathrm{M}=18.83 ; \mathrm{SD}=1.08$ ), with an average age of 18.81 years old $(\mathrm{SD}=0.96)$, with 479 first-year students $(48.75 \%)$. In terms of origin, there are 692 students $(70.36 \%)$ from inland China, 231 students from Hong Kong and Macao, and 44 students from Taiwan.

\subsection{A Questionnaire Measuring the Relationship Between WeChat Use Intensity and Social Capital of College Students}

Appropriate scales were used to measure the main research variables, including "intensity of WeChat use", "Wechat moment and social contact", "self-esteem", "college life satisfaction" and "bridging social capital". The demographic 
variables included four background variables, including gender, age, college year and place of origin. The specific contents of the structured questionnaire are as follows:

1) Intensity of WeChat Use

In this study, six aspects of WeChat use intensity were measured, including the number of WeChat friends, use density, use feelings and sense of belonging, etc. Students answered according to their actual feelings. This part is scored on a five-point scale ( $1=$ strongly disagree, $5=$ strongly agree), and the internal consistency reliability of the WeChat intensity test item Cronbach's $\alpha$ is 0.821 .

\section{2) WeChat Use And Socialization}

In this study, WeChat use behavior was measured from three aspects, including communicating with classmates, checking Wechat moments' information and maintaining contact with old friends. Students responded according to their actual feelings. Using five-point scale score $(1=$ very not agree, $5=$ strongly agree $)$, WeChat use social internal consistency reliability test purposes Cronbach's $\alpha$ is 0.753 .

\section{3) Self-esteem}

In this study, the Rosenberg self-esteem scale was used to measure students' self-esteem from five aspects, including personal self-worth judgment, number of WeChat friends, density of use, feelings of use and sense of belonging, etc. Students answered questions based on their actual feelings. A five-point likert scale was used $(1=$ strongly disagree, $5=$ strongly agree). One of the topics, "You don't think you have anything to be proud of", is the reverse question. The internal consistency reliability of the self-Esteem test topic Cronbach's $\alpha$ is 0.78 .

\section{4) College Life Satisfaction}

College life satisfaction mainly measures the degree of satisfaction of the respondents with their campus life, including five questions such as personal campus life status, feelings and sense of growth and acquisition. Students answer according to their actual feelings. For this part, 5-point likert scale is adopted (1= strongly disagree, 5= strongly agree). The higher the score, the higher the satisfaction. University life satisfaction internal consistency reliability test purpose Cronbach's $\alpha$ is 0.832 .

\section{5) Bridging Social Capital}

In this study, the measurement of bridging social capital was modified by using existing scales. Quan-Haase and Wellman (2004) designed and tested the classical scale of social capital. The original scale included three research dimensions, and this paper only selected the dimension of bridging social capital and WeChat intensity for regression analysis. Bridging social capital mainly tests students' behavior and attitudes from nine aspects. Topics include, "do you think you are part of a learning and living community?" and "are you interested in what's going on at school?" A five-point scale is used ( $1=$ strongly disagree, $5=$ strongly agree). Internal consistency reliability bridging social capital subject Cronbach's alpha was 0.921 .

\section{Empirical Analysis of the Relationship Between WeChat Use Intensity of College Students and Bridging Social Capital}

Based on the combing of the concept of social capital and the empirical study on the relationship between WeChat use and social capital of college students, this study is helpful to discuss the relationship between WeChat use intensity and bridging social capital, and to verify the moderating effect of self-esteem and campus life satisfaction as interference variables.

\subsection{Study of Variable Correlation Analysis}

In terms of demographic variables and major research variables, the independent variable "campus life satisfaction" has a significant negative correlation with "gender", indicating that women are more disappointed in campus life than men. There is a significant positive correlation between "WeChat use social behavior" and "origin of student", indicating that students from Hong Kong, Macao and Taiwan are more willing to use online tools to communicate and communicate with their classmates compared with students from mainland China, which is actually not conducive to individual integration into college collective life.

In terms of main research variables, "bridged social capital" is significantly positively correlated with "WeChat intensity of use", "WeChat intensity of use social behavior", "self-esteem" and "campus life satisfaction", indicating that the greater the intensity of WeChat use, the stronger the ability to bridge social capital, and the greater the self-esteem, the more able to intervene in bridging social capital, and the greater the campus satisfaction, the more able to intervene in bridging social capital. The first, second and third hypotheses are supported. College students with higher self-esteem 
and social skills are more likely to establish more satisfactory community relations through the use of WeChat. College students with higher self-esteem are more likely to gain bridging social capital in the use of social media.

3.2 The Intensity of WeChat Use on the Predictive Effect of Bridging Social Capital and the Regulating Effect of Self-Esteem and Campus Life Satisfaction

1) Analysis of Self-esteem Regulation Effect

In this study, the predictive effect of WeChat use intensity on bridging social capital was analyzed by hierarchical regression. First, the demographic variable was put into the first layer of the regression model to control the effect of the demographic variables on the variables, then the intensity of the use of WeChat and self-esteem in the second layer, and in the third layer into the use of WeChat intensity and self-esteem accumulation, in order to test the effect of self-esteem regulation.

Table 2. The intensity of WeChat use and bridging social capital: The regulating effect based on self-esteem

\begin{tabular}{|c|c|c|c|c|c|c|}
\hline \multirow[t]{2}{*}{ Predictive factor } & \multicolumn{2}{|l|}{ Model I } & \multicolumn{2}{|l|}{ Model II } & \multicolumn{2}{|l|}{ Model III } \\
\hline & Scaled Beta & $\mathrm{P}$ & Scaled Beta & $\mathrm{P}$ & Scaled Beta & $\mathrm{P}$ \\
\hline \multicolumn{7}{|l|}{ Control variables } \\
\hline Age & -.060 & & -.096 & * & -.095 & * \\
\hline Gender & -.079 & & -.123 & ** & -.128 & $* *$ \\
\hline Source Land & -.022 & & -.019 & & -.018 & \\
\hline \multicolumn{7}{|l|}{ Predictive variables } \\
\hline WeChat usage Strength & & & .248 & ** & 240 & ** \\
\hline Self - esteem & & & .467 & ** & .450 & ** \\
\hline \multicolumn{7}{|l|}{ Interference variables } \\
\hline WeChat use strength by self-esteem & & & & & -.076 & \\
\hline $\mathrm{N}=361$ & $\mathrm{~F}=1.163$ & & $\mathrm{~F}=41.828$ & $* *$ & $\mathrm{~F}=35.555$ & $* *$ \\
\hline & Adj. $R^{2=} .01$ & & Adj. $R^{2}=.362$ & & Adj. $R^{2}=.365$ & \\
\hline
\end{tabular}

Table 2 is a regression analysis of the intensity of WeChat use as a predictor of bridging social capital = (self-esteem regulation). The results show that the greater the intensity of WeChat use, the more favorable it is for the promotion of bridging social capital, and the adjustment effect as self-esteem is remarkable. Assuming four is validated, self-esteem can indeed interfere with the impact of WeChat's intensity on bridging social capital.

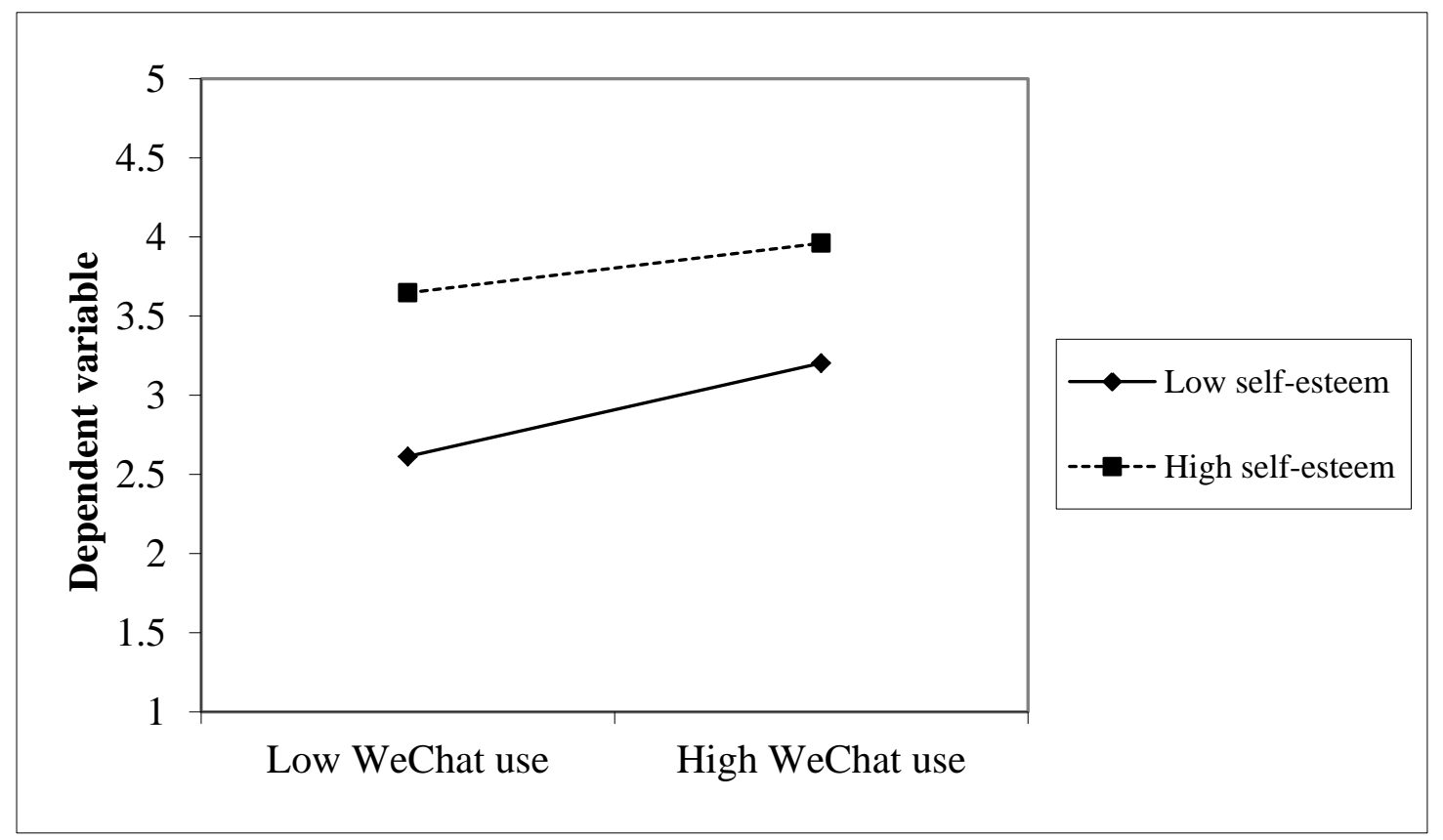

Figure 1. Regulation effect of low self-esteem and high self-esteem

2)Analysis of The Adjustment Effect of Campus Satisfaction 
Table 3. WeChat use intensity and bridging social capital (campus satisfaction adjustment effect)

\begin{tabular}{|c|c|c|c|c|c|c|}
\hline \multirow[t]{2}{*}{ Predictive factor } & \multicolumn{2}{|l|}{ Model I } & \multicolumn{2}{|l|}{ Model II } & \multicolumn{2}{|l|}{ Model III } \\
\hline & Scaled Beta & $\mathrm{P}$ & Scaled Beta & $\mathrm{P}$ & Scaled Beta & $\mathrm{P}$ \\
\hline \multicolumn{7}{|l|}{ Control variables } \\
\hline Age & -.060 & & -.051 & & -.055 & \\
\hline Gender & -.079 & & -.052 & & -.052 & \\
\hline Source Land & -.022 & & -.095 & & -.093 & \\
\hline \multicolumn{7}{|l|}{ Predictive variables } \\
\hline WeChat usage Strength & & & .300 & $* *$ & 293 & ** \\
\hline Self - esteem & & & 481 & $* *$ & .484 & ** \\
\hline \multicolumn{7}{|l|}{ Interference variables } \\
\hline $\begin{array}{l}\text { WeChat use strength by Campus } \\
\text { Satisfaction }\end{array}$ & & & & & -.076 & \\
\hline $\begin{array}{l}\text { Satisfaction } \\
\mathrm{N}=361\end{array}$ & $\begin{array}{l}F=1.125 \\
\text { Adj. } R^{2=} .01\end{array}$ & & $\begin{array}{l}\mathrm{F}=46.321 \\
\text { Adj. } \mathrm{R}^{2}=.386\end{array}$ & $* *$ & $\begin{array}{l}\mathrm{F}=39.076 \\
\text { Adj. } \mathrm{R}^{2}=.388\end{array}$ & ** \\
\hline
\end{tabular}

Notes: ${ }^{1} * \mathrm{P}<0.05, * * \mathrm{P}<0.01 .{ }^{2}$ Sex: Male $=1$, female $=2 .{ }^{3}$ Source Land: Mainland China $=1$, Not Mainland China $=2$

Table 3 provides a regression analysis of the intensity of WeChat use as a predictor of bridging social capital. The analysis results show that the greater the intensity of WeChat use, the more favorable it is for the promotion of bridging social capital, and the adjustment effect as self-esteem is remarkable. Assuming four is validated, self-esteem can indeed interfere with the impact of WeChat's intensity on bridging social capital.

In the effect of campus satisfaction on the intensity of WeChat use and the regulation of bridging social capital, the data is not significant, so it is assumed that five is not adopted.

\section{Conclusion}

The above empirical evidence shows that the use of WeChat in college students on campus life satisfaction effect. Therefore, when studying the integration of college students ' campus life, we should not neglect the role of communication as a kind of social capital. The main enlightenment of this study, the present is as follows:

1) From the degree of integration into campus life, social media contributes to the accumulation and maintenance of social capital for college students. This is also closely related to the previous study on the relationship between social capital and the "weak relationship" of the network. WeChat use helps college students to maintain the "network weak connection" contact. The intensity of WeChat's use predicts the level of maintaining social capital and the "power of weak bonds" in network communication. These potentially useful linkages are often a source of new information and interpersonal resources. From the point of view of interpersonal interaction of campus life, some studies point out that the campus interpersonal interaction of college students has an important influence on the socialized development of students. Therefore, It is very important for college students with weak self-esteem to promote their integration into harmonious university life, to play the role of new media, and to provide educational activities in line with students ' expectations and needs.

2) The ability to maintain social capital also helps to eliminate the loneliness of college students in the face of new campus life. When self-esteem and satisfaction are the interference variables, the research proves that the intensity of WeChat use of college students is positively correlated with social capital, and the intensity of WeChat use has a direct effect on campus life satisfaction, and self-esteem has a regulating effect between the intensity of WeChat use and social capital.

3) The scientific and rational use of new media has a positive guiding effect on the physical and mental development of college students in the new era. As a comprehensive social media embedded in the daily life of college students, WeChat plays an important role in the process of forming and maintaining social capital for college students. The results of the data analysis show that there is no real difference in demographics. In the future research outlook, the coverage of the study sample can be further expanded, in the vertical data collection, the continuous collection of longitudinal data, will also contribute to the further deepening of the study.

\section{Acknowledgment}

The research is the staged achievement of the following projects: Guangdong Educational Science Planning Topic (The 19th CPC National Congress Spirit Research Project), Project name: Research on Linkage Mechanism of Ideological and Political Theory Course and New Media and New Technology in New Era, Project Grant No. 2016GZMZGJ04, and 2017 Guangzhou Philosophy and Social Sciences "13th Five - Year Plan” Special Topic on Marxist Theory and Practice, Project name: Research on Making Ideological and Political Work Live with New Media and New Technology, Project 
Grant No. 2018JKSJD83. This paper is sponsored by the Zhuhai excellent counselor program and the 19th batch of teaching reform research projects of Jinan University Project Grant No. JG2017034.

\section{References}

Bourdieu, P., \& Wacquant, L. (1992). An Invitation to Reflexive Sociology. Chicago: University of Chicago Press.

Burt, R. S. (1997). The Contingent Value of Social Capital. Administrative Science Quarterly, 42(2), 339-365. https://doi.org/10.2307/2393923

Cao, C., Guo, S. S., Zhao, Y., Sun, Y., Qi, Q., \& Kang, L. Y. (2015). Characteristics and causes of WeChat friend circle posts of college students. Chinese Youth Research, (04), 69-73. https://doi.org/10.3969/j.issn.1002-9931.2015.04.013

Coleman, J. S. (1988). Social capital in the creation of human capital. American Journal of Sociology, 94(Supplement), 95-120. https://doi.org/10.1086/228943

Ellison, N. B. (2006). The Benefits of Facebook "Friends:" Social Capital and College Students' Use of Online Social Network Sites. Journal of Computer-Mediated Communication, 12. https://doi.org/10.1111/j.1083-6101.2007.00367.x

Granovetter, M. S. (1973). The strength of weak ties. American Journal of Sociology, 78(6), 1360-1380. https://doi.org/10.1086/225469

Huysman, M., \& Wulf, V. (2004). How Does the Internet Affect Social Capital? MIT Press.

Jin, C. H. (2013). The role of Facebook users'self-systems in generating social relationships and social capital effects. New Media \& Society, 17(4). https://doi.org/10.1177/14614448813506977

Kramer, M. W., Lee, S. K., \& Guo, Y. (2018). Using communication technology to manage uncertainty during organizational assimilation: information-seeking and information-giving. Western Journal of Communication, 1-22. https://doi.org/10.1080/10570314.2018.1518538

Lee, \& Kyong, S. (2014). The impact of social capital in ethnic religious communication networks on Korean immigrant's intercultural development. International Journal of Intercultural Relations, 43, 289-303. https://doi.org/10.1016/j.ijintrel.2014.10.001

Leonardi, P. M., \& Meyer, S. (2015). Social media as social lubricant: how ambient awareness eases knowledge transfer. Social Science Electronic Publishing. https://doi.org/10.1177/0002764214540509

Leonardi, P. M., \& Vaast, E. (2017). Social media and their affordances for organizing: a review and agenda for research. Academy of Management Annals, 11(1), 150-188. https://doi.org/10.5465/annals.2015.0144

Paul, A. S., \& Kwon, S. W. (2002). Social Capital: Prospects for A New Concept. The Academy of Management Review, 27(1), 17-40. https://doi.org/10.5465/amr.2002.5922314

Putnam, R. D. (2004). Bowling alone: The collapse and revival of American community. Journal of the American College of Radiology, 1(12), 997. https://doi.org/10.1145/358916.361990

Yu, X., \& Wang, Y. P. (2014). Research on influencing factors of college students' public opinion expression in the context of social network. China Youth Research, (10), 97-104. https://doi.org/10.3969/j.issn.1002-9931.2014.10.018

Zhou, Z. K., Lian, S. L., Tian, Y., Niu, G. F., \& Sun, X. J. (2017). The relationship between the use of social networking sites and life satisfaction of adolescents: a 0 model with adjustment. Psychological Development and Education, 33(03), 297-305. https://doi.org/10.16187/j.cnki.issn1001-4918.2017.03.06

\section{Copyrights}

Copyright for this article is retained by the author(s), with first publication rights granted to the journal.

This is an open-access article distributed under the terms and conditions of the Creative Commons Attribution license which permits unrestricted use, distribution, and reproduction in any medium, provided the original work is properly cited. 